\title{
Investigation of Sleep Quality of Nurses and Its Relationship with Musculoskeletal Disorder Prevalence and Job Stress
}

\author{
Behnam Moradi ${ }^{1}$ iD , Samira Barakat ${ }^{2, *}$ \\ ${ }^{1}$ MSc, Department of Health, Safety and Environment, School of Public Health and Safety, Shahid Beheshti University of \\ Medical Sciences, Tehran, Iran \\ ${ }^{2}$ MSc, Department of Occupational Health Engineering, School of Public Health, Isfahan University of Medical Sciences, \\ Isfahan, Iran \\ * Corresponding Author: Samira Barakat, Department of Occupational Health Engineering, School of Public Health, Isfahan \\ University of Medical Sciences, Isfahan, Iran.Email: samirabarakat.ohs@gmail.com
}

Received: 09/09/2020

Accepted: 13/01/2021

How to Cite this Article: Moradi B, Barakat S. Investigation of Sleep Quality of Nurses and Its Relationship with Musculoskeletal Disorder Prevalence and Job Stress. J Occup Hyg Eng. 2021; 8(1): 26-36. DOI: $10.29252 /$ johe.8.1.26

\section{Abstract}

Background and Objective: Sleep is one of the basic human needs that can cause physical and psychological problems if it is not met properly. Musculoskeletal disorders and job stress are among the most important concerns of staff in organizations, especially hospitals. This study aimed to determine the sleep quality of nurses and its relationship with musculoskeletal disorder prevalence and job stress.

Materials and Methods: This descriptive-analytical study was conducted on 218 nurses working at two hospitals in Isfahan, Iran. The data were collected using the Pittsburgh sleep quality, Nordic questionnaires, as well as Health and Safety Executive job stress questionnaire. Moreover, the nurses' body posture was investigated using the Quick Exposure Check (QEC) method. The collected data were analyzed in SPSS software (version 21).

Results: The sleep quality of $67.31 \%$ of the nurses was undesirable. According to the results, the sleep quality had a significant relationship with the prevalence of musculoskeletal disorders $(\mathrm{P}=0.002, \mathrm{R}=0.514), \mathrm{QEC}$ final score $(\mathrm{P}<0.001, \mathrm{R}=0.589)$, and job stress $(\mathrm{P}<0.001, \mathrm{R}=-0.793)$.

Conclusion: In this study, sleep quality was regarded as an effective parameter in the incidence of musculoskeletal disorders and job stress among nurses. Therefore, lack of attention to the sleep quality of nurses not only deteriorates their health but also has negative effects on providing services to the patients.

Keywords: Job Stress; Musculoskeletal Disorders; Nurses; QEC Method; Sleep Quality 


\section{بررسى كيفيت خواب يرستاران و ارتباط آن با شيوع اختلالات اسكلتى- عضلانى و}

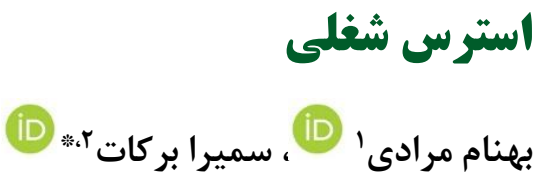

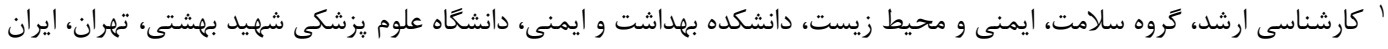

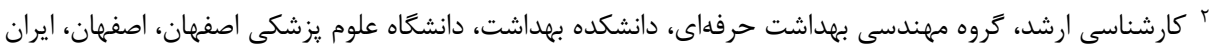

* نويسنده مسئول: سميرا بركات، كروه مههندسى بهداشت حرفهاى، دانشكده بهداشت، دانشًاه علوم يزشكى شهيد بهشتى، تهران، ايران. ايميل: samirabarakat.ohs@gmail.com

\section{جكيده}

سابقه و هدف: خواب يكى از نيازهاى اساسى انسان است كه در صورت عدم رفع اين نياز باعث بروز مشكلات

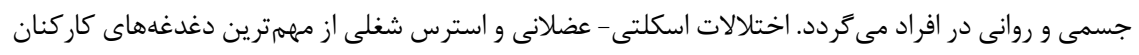

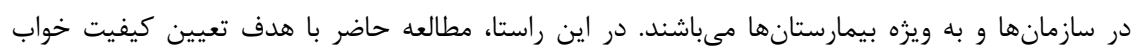

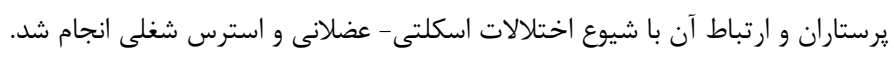

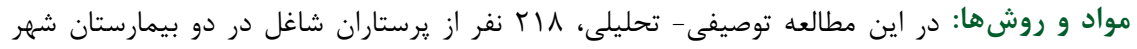

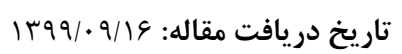

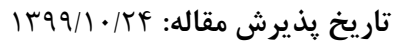
تمامى حقوق نشر براى دانشكاه علوم يزشكى همدان محفوظ است.

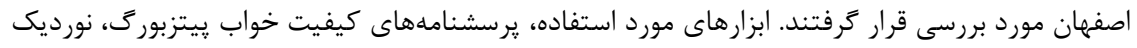

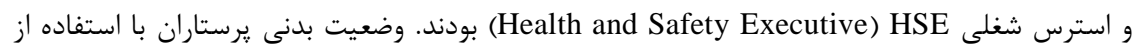

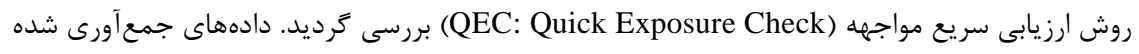

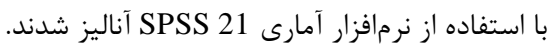

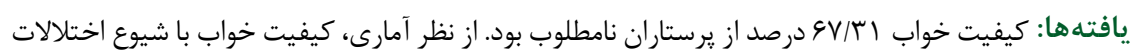

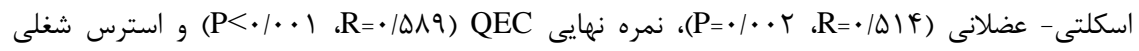

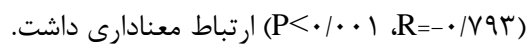

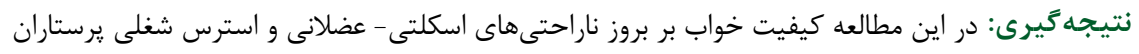

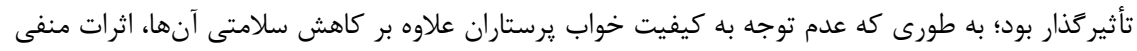
بر ارائه خدمات به بيماران دارد.

وازَّان كليدى: اختلالات اسكلتى- عضلانى؛ استرس شغلى، يرستاران؛ روش QEC؛ كيفيت خواب

بهداشتى از قبيل ناراحتى هاى كوارشى، قلبى، عدم تمركز و دقت

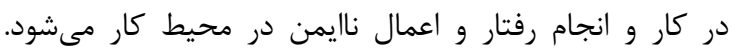

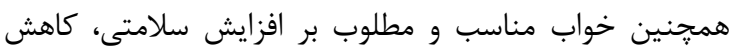

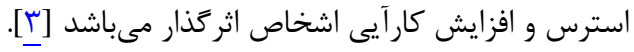

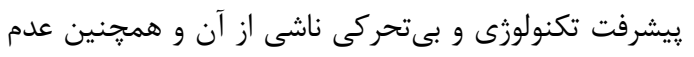

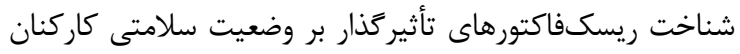

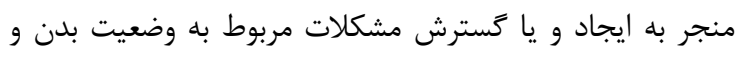

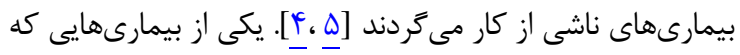

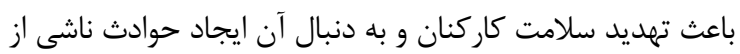

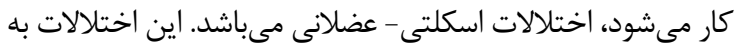

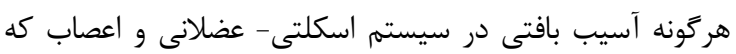

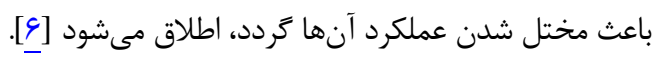

خواب يكى از فاكتورهاى تأثير حذار بر سلامت انسان مىباشد. خواب يك مكانيسم فيزيولوزيكى در بدن است كه باعث بازيابى إنى

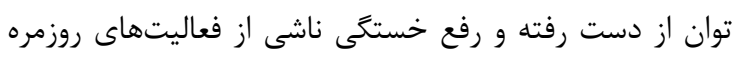

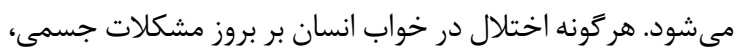

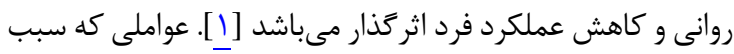

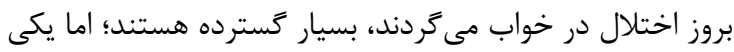

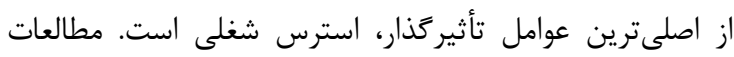

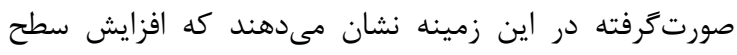
استرس شغلى باعث افزايش خطر كاهش كيفيت خواب و دمر در نهايت بروز اختلالات خواب مىشود [ب]. در اين راستا، Ayas و و

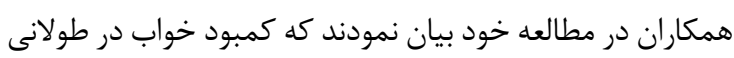
مدت علاوه بر بروز مشكلات جسمى و روانى سبب ايجاد مشكلات 
بيمارستانها هستند [Tr]]. كاركنان بيمارستان جمعيت متنوعى

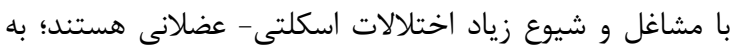

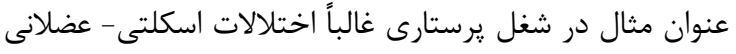

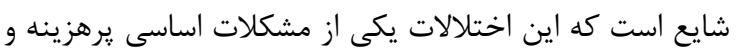

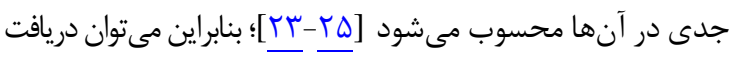

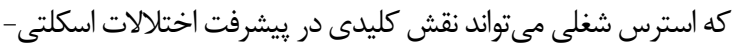

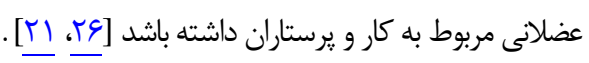

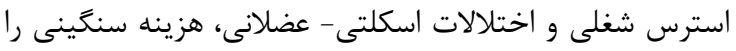

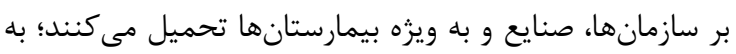
طورى كه در ايالات متحده به تنهايى سالانه دهها ميليارد دلار هزينه صرف كارهاى تشخيصى و درمانى اختلالات اسكلتى

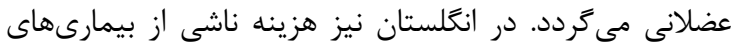

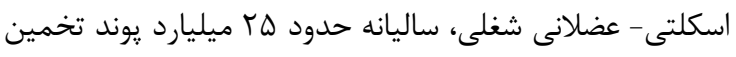

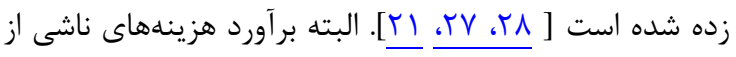
استرس شغلى و اختلالات اسكلتى - عضلانى دشوار است؛ اما شايد بزركترين هزينهاى كه بر اثر اين دو فاكتور يديد مى آيد و محاسبه

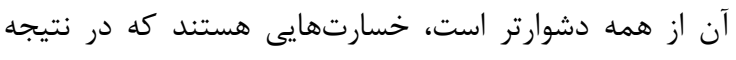

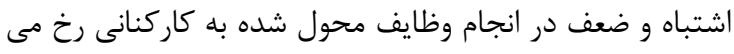

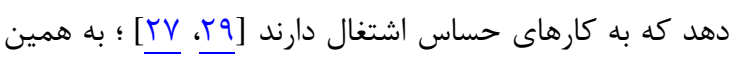

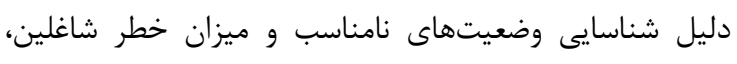

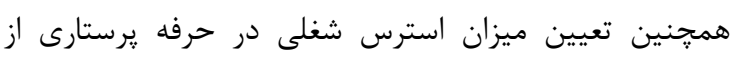

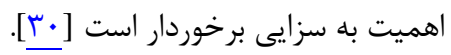

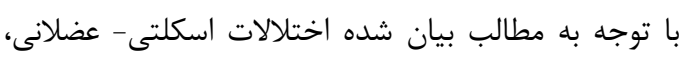

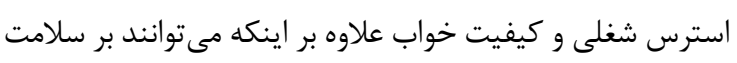

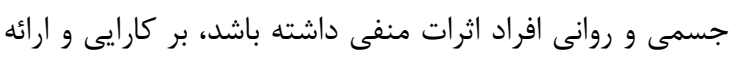
كيفيت خدمات توسط يرستاران و زندگى فرى و اجتماعى آنها

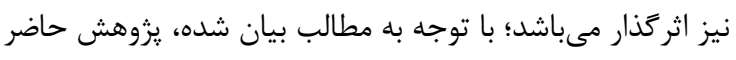

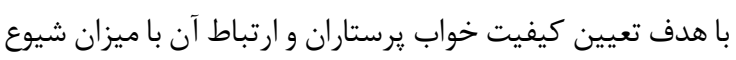

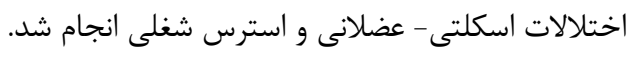

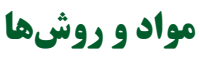

جامعه مورد بررسى در مطالعه توصيفى- تحليلى حاضر كه

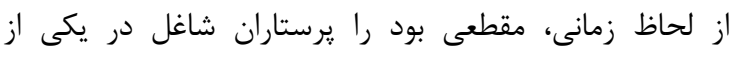

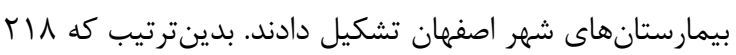

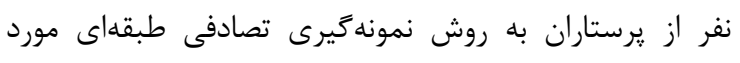

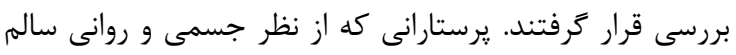

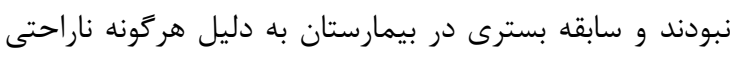

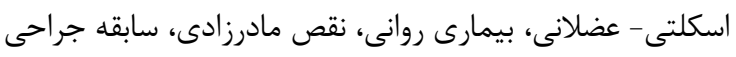

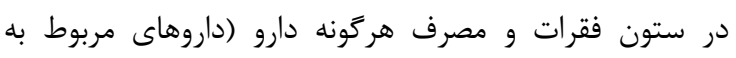

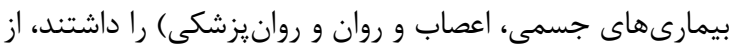

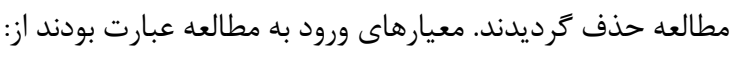

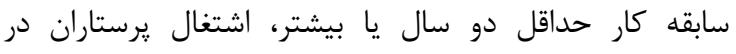

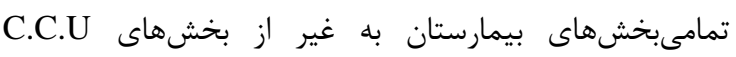

از عوامل تأثيركذار بر بروز و پيشرفت اختلالات اسكلتى - عضلانى مىتوان به اعمال نيروى زياد، حركات تكرارى، بلند كردن اجسام يا بـاني

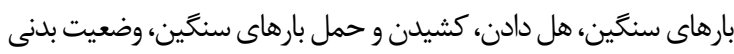

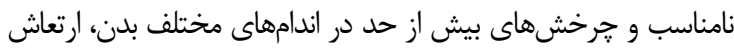

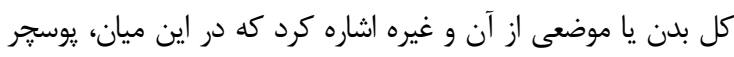

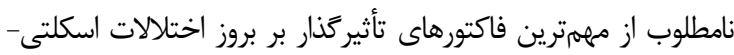

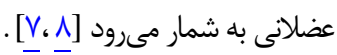

NIOSH: ) بنا بر ززارش مؤسسه ملى بهداشت و ايمنى كارود

،National Institute of Occupational Safety and Health بيمارىهاى اسكلتى - عضلانى مرتبط با كار، يس از بيمارىهاى

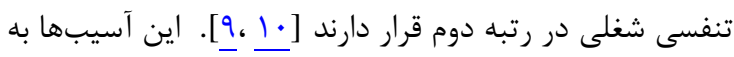

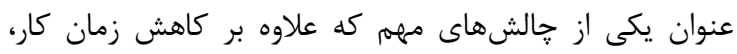

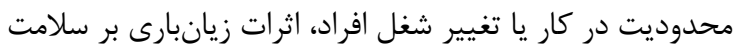

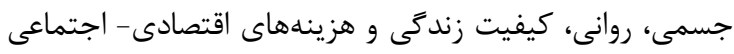
داشته است [111] مطابق با آمار ارائه شده از سوى اداره كار آمريكا، بF د درصد

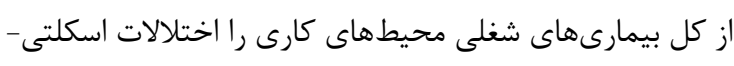

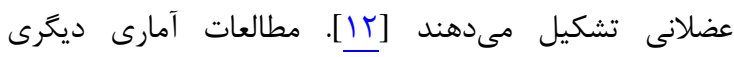

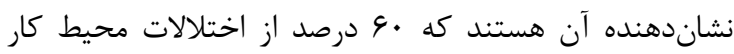

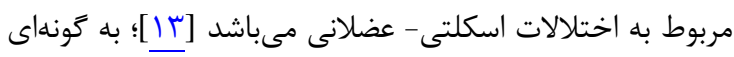

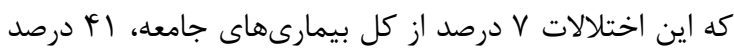

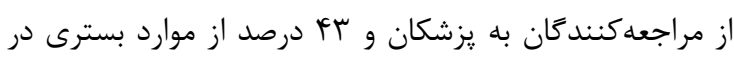

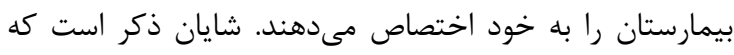

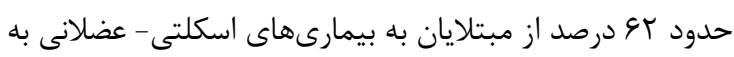
نوعى محدوديت حركتى دجار مىشوند [1 أ]

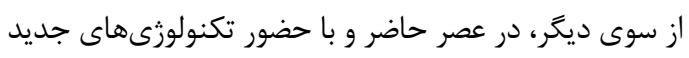

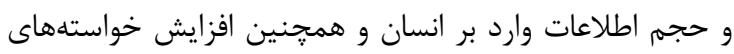
فرد در جامعه و محيط شغلى در سطوح مختلف، فشارهاى

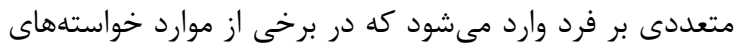

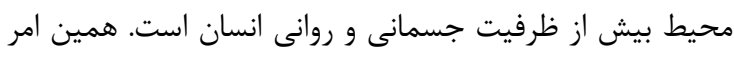

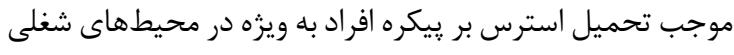

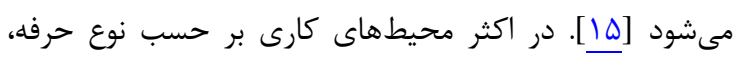
مقدارى تنش و استرس وجود خواهد داشت [19].

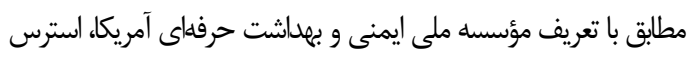

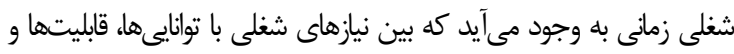

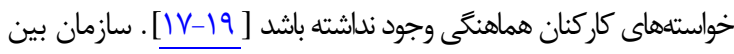

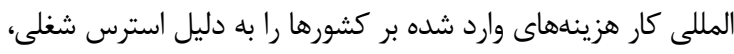

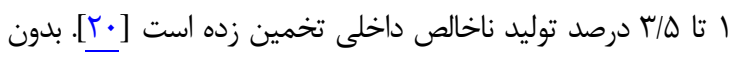

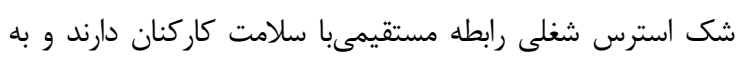
همين دليل بايد به صورت تخصصى و موشكافانه مورد بررسى قرار بكيرند [rI] امروزه يكى از سازمانهايى كه كاركنان آن به طور جدى دركير

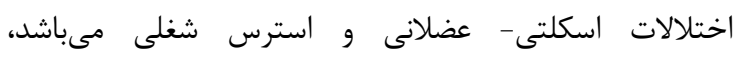


مىشود. بر پايه روش QEC، اندامهاى بدن براساس يوسجرهايى

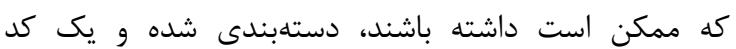

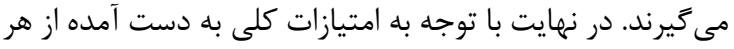
يوسجر كارى، سطح اقدامات اصلاحى و انجام مداخله اركونوميكى ندي

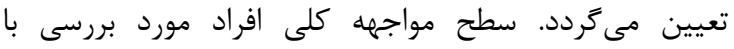
ريسكفاكتورهاى اختلالات اسكلتى - عضلانى براساس امتياز كل فرداد Q و از طريق معادله زير محاسبه مى گردد:

مجموع امتياز نواحى جهار كانه بدن = امتياز كل 162

عدد IV9 براى كارهايى كه حمل و نقل دستى بار دارند و عدد

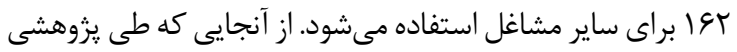

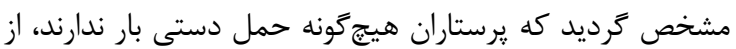

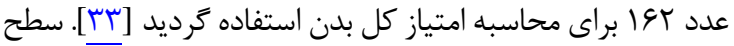

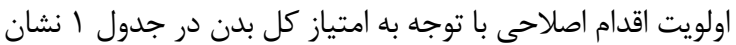

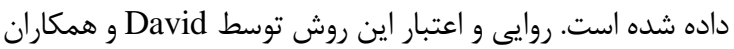

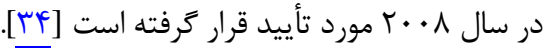
مرحله بنجهم: بررسى استرس با استفاده از يرسشنامه استاندارد استرس شغلى مؤسسه HSE انغخلستان برسان Health and Safety) HSE يرسشنامه استرس شغلى مؤسلى

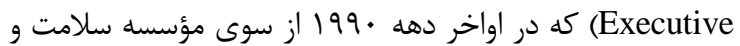

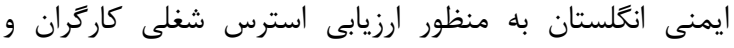

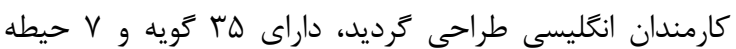
مىباشد [هץ]. حيطههاى :رسشنامه عبارت هستند ازئ تقاضا،

جدول ا: سطح اولويت اقدام اصلاحى براى امتياز كل بدن

\begin{tabular}{|c|c|c|c|}
\hline يِشنهادى اقدام & وامتياز كل بدن براى بدون حمل & ريسك & سطح \\
\hline انجام مطالعات & $9 \Delta>$ & پايين & 1 \\
\hline بيشترى لازم & $11-9 \Delta$ & متوسط & $r$ \\
\hline بايد اقدامات & & & \\
\hline آينده نزديك & $\Delta r-1 \| r$ & بالا & $r$ \\
\hline بايد اقدامات & & & \\
\hline 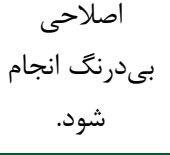 & $\| 1 r<$ & بسيار بالا & r \\
\hline
\end{tabular}

و (Intensive care units) I.C.U ،(Coronary care unit)

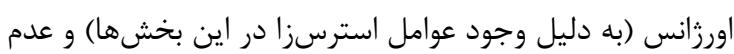
مصرف هركونه داروى مربوط به اختلالات اسكلتى - عضلانى و داني

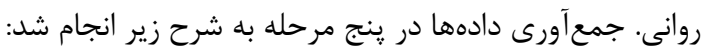
مرحله اول: بررسى ويزگى هاى دموكر افيك افراد باد با استفاده

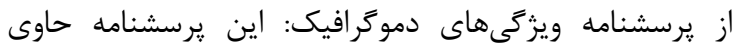
سؤالاتى در مورد سن، جنس، سابقه كار، وضعيت تأهل، فعاليت

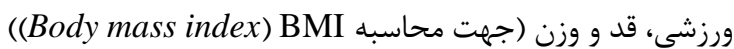
بود كه توسط افراد مورد بررسى تكميل كرديد. مرحله دوم: بررسى كيفيت خواب با استفاده از يرسشنامه كيفيت خواب پِيترزبورى

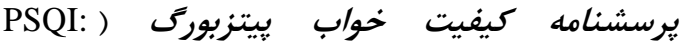

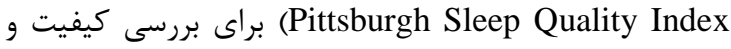
الكوهاى خواب در يك ماه كذشته مورد استفاده قرار مى كيرد.

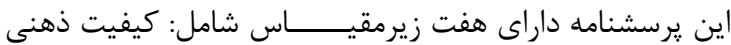

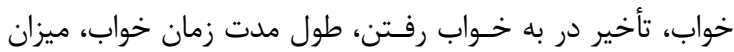

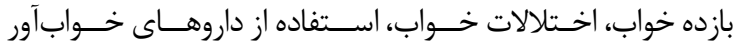

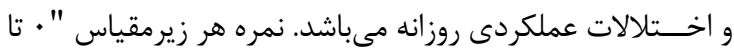

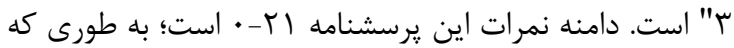

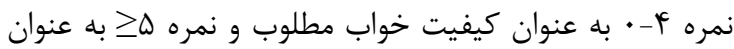

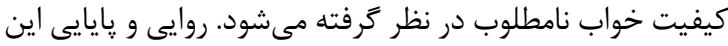

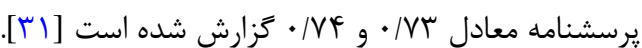
مرحله سوم: بررسى شيوع اختلالات اسكلتى- عضلانى با بادئ

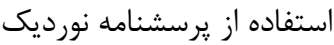
يرسشنامه نورديك براى ثبت شكايات اسكلتى - عضلانى در

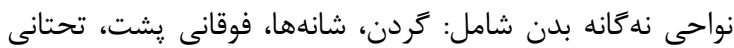

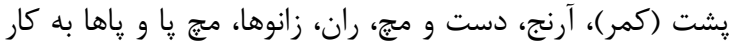

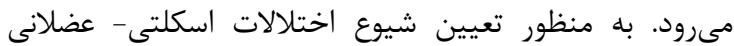

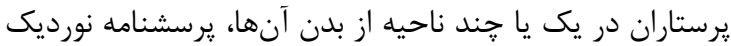

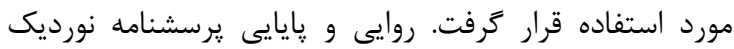
توسط مختارى نيا و همكاران مورد تأييد قرار كرفته است [بست]. مرحله جهارم: ارزيابى ريسكفاكتورهاى اركونومى يرستاران

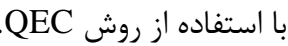

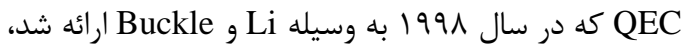
يك روش ارزيابى سريع سطح مواجهه با خطر اختلالات اسكلتى -

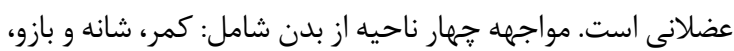
مجج دست و دست و كردن كه در معرض بزركترين خطرات

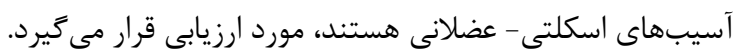
در اين روش با توجه به مشاهده محقق و پاسخ فرد ارزيابى شونده،

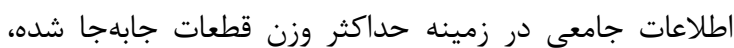
ميانكين زمانى انجام كار مورد نظر، حداكثر نيروى اعمال شده درد

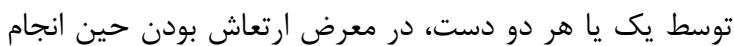

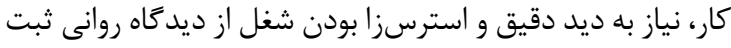


معادل ه • • • در نظر گرفته شد.

نتايج

در يزوهش حاضر يرستاران شاغل در يكى از بيمارستانهاى شهر

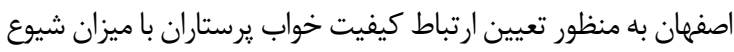
اختلالات اسكلتى - عضلانى و استرس شغلى مورد مطالعه قرار كرفتند.

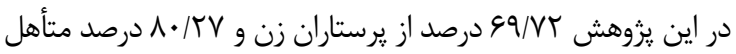

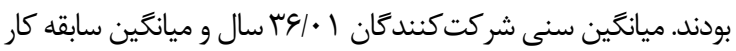

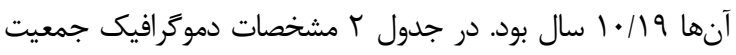
مورد مطالعه نشان داده شده است. ميزان شيوع اختلالات اسكلتى- عضلانى در بين يرستاران سو/ درصد)، گردن (له/

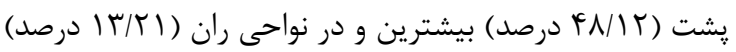

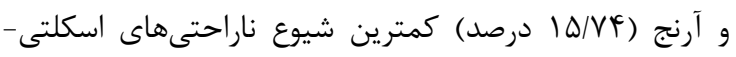

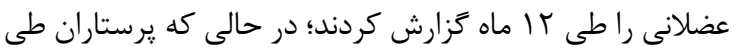
V روز كذشته، بيشترين شيوع آسيبهاى اسكلتى - عضلانى راد مج دست (r/N/K

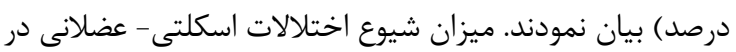
نواحى مختلف بدن در نمودار ا نشان داده شده است دئ.

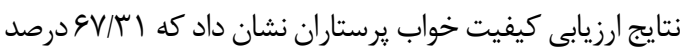
از آنها داراى كيفيت خواب نامطلوب هستند. در ارزيابى ريسك دئي

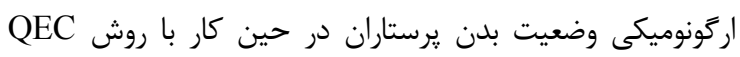

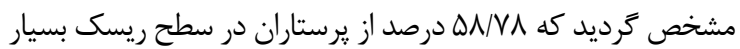

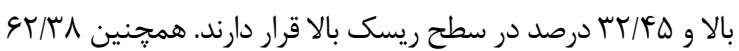

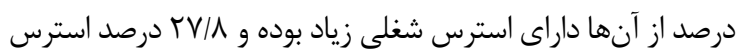
شغلى متوسط داشتند. جدول r درصد فراوانى هريك از سطوح
كنترل، حمايت مسئولين، ارتباط، نقش و تغييرات. نمرهزذارى

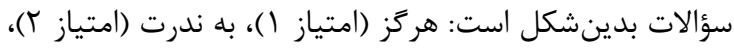

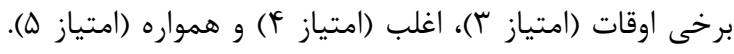

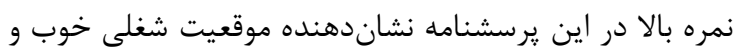

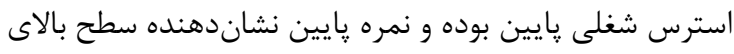

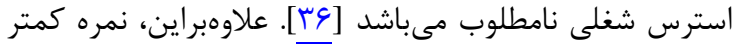

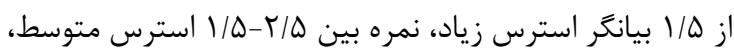

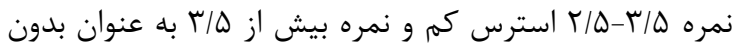

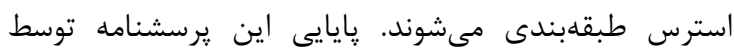

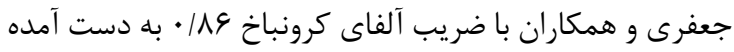

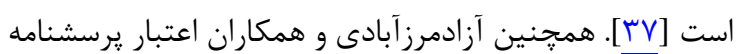

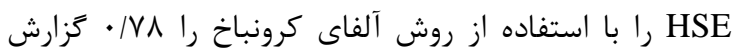

نمودند [ب阝].

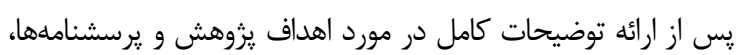

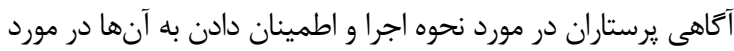

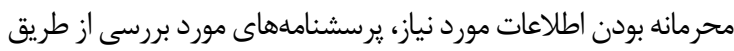
مصاحبه حضورى و با رضايت كامل يرستاران تكميل شدند. زمان

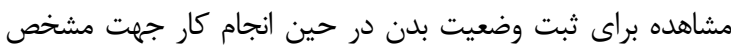

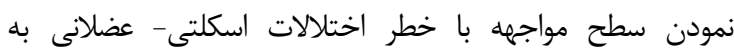

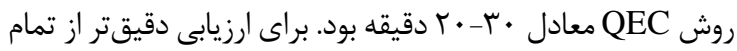

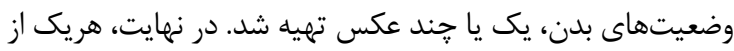

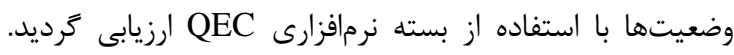

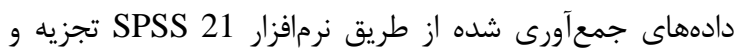

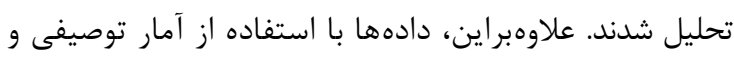

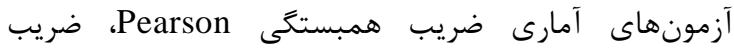
همبستخى فى و كرامر، مجذور خى و ركر سيون لجستيك مورد بررسى قرار گرفتند. سطح معنادارى براى آزمونهاى هرئى آمارى

جدول r: مشخصات دموكرافيك جمعيت مورد مطالعه

\begin{tabular}{|c|c|c|c|}
\hline درصد فروانى & ميانغين土|نحراف معيار & & متغير \\
\hline- & $r \varepsilon / \cdot 1 \pm \varepsilon / q V$ & & سن (سال) \\
\hline- & $1 \cdot 119 \pm 9 / 19$ & & سابقه كار (سال) \\
\hline- & $r r / q r \pm r / I r$ & $(\varepsilon$ & BMI (كيلو \\
\hline Gq/VT & - & زن - ان & \multirow{2}{*}{ جنسيت } \\
\hline$r \cdot / r \wedge$ & - & مرد & \\
\hline $19 / V \pi$ & - & 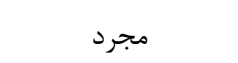 & \multirow{2}{*}{ وضعيت تأهل } \\
\hline$\Lambda \cdot / r V$ & - & متأهل & \\
\hline $10 / 9$ & - & روز كار & \multirow{2}{*}{ نوبت كارى } \\
\hline$\Lambda F / \mathcal{F}$ & - & نوبت كار & \\
\hline$I F / T Y$ & - & انجام فعاليت ورزشى & \multirow{2}{*}{ فعاليت ورزشى } \\
\hline$\Lambda \Delta / V \Lambda$ & - & عدم فعاليت ورزشى & \\
\hline
\end{tabular}




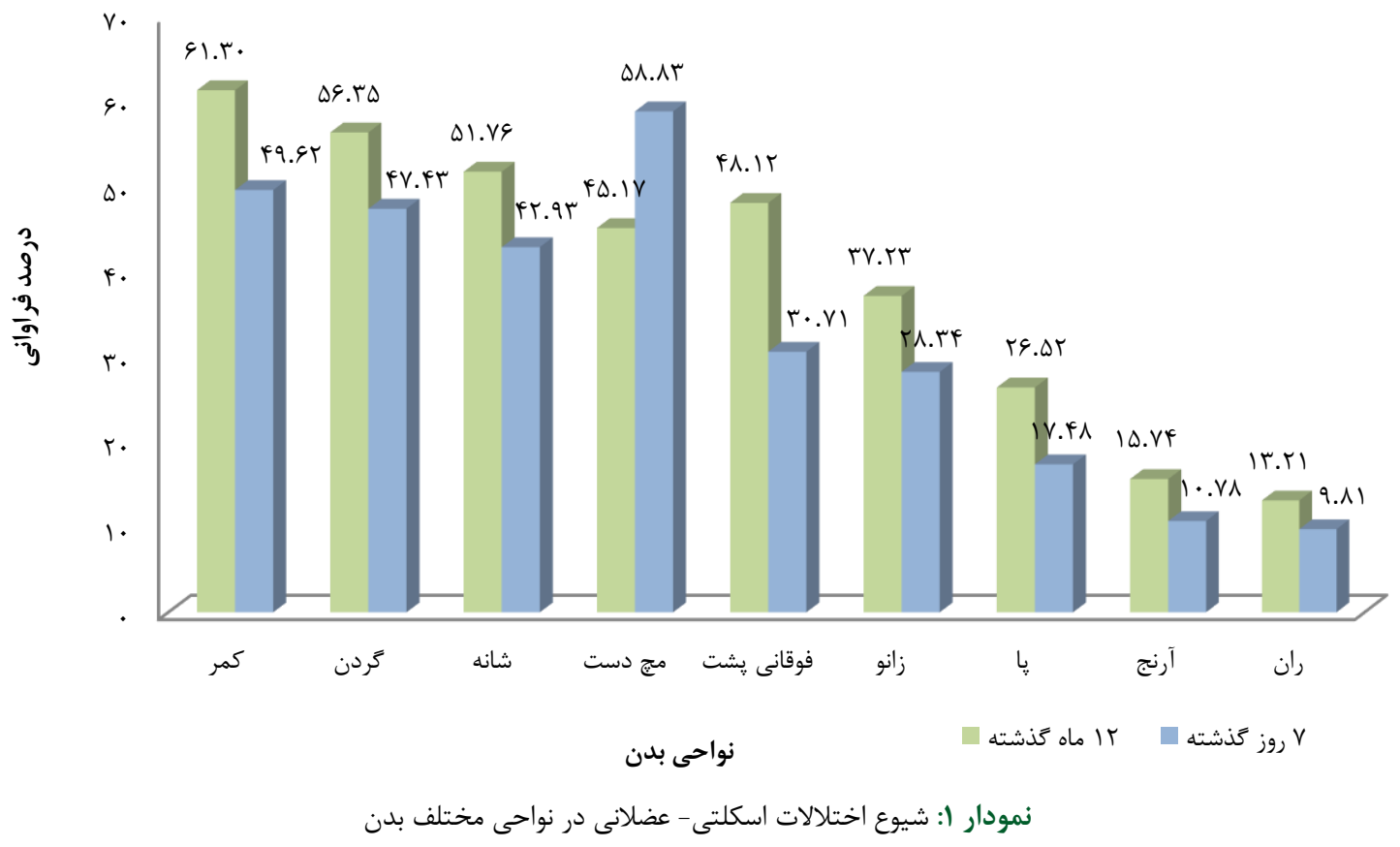

مستقيم و معنادارى وجود دارد ( عبارت ديخر با افزايش نمره كيفيت خواب، شيوع وجنادود اختلالات

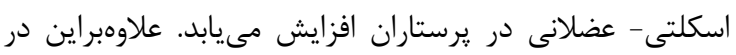
تحليل ركرسيون لجستيك به منظور تعيين ارتباط كيفيت خواب دئي

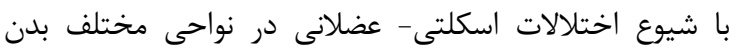

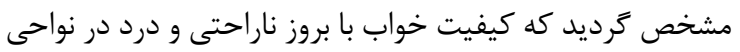
كمر (1)

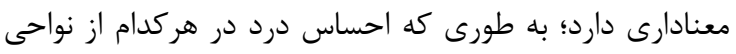

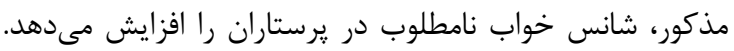

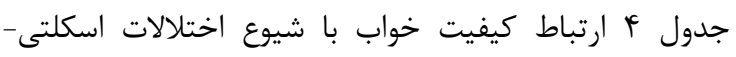
عضلانى در نواحى مختلف بدن را نشان مى دهدي.

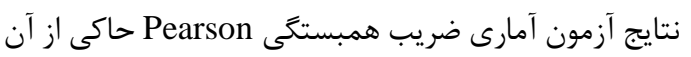
هستند كه كيفيت خواب با نمره نهايى

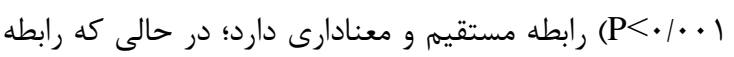

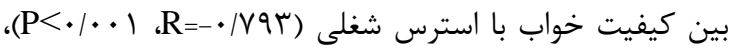

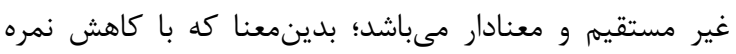

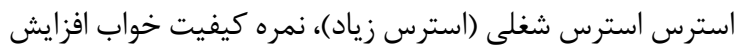

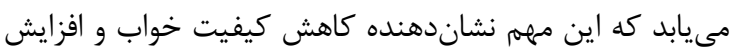

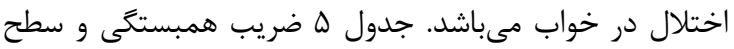

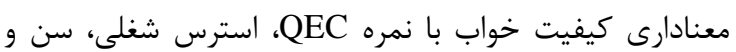

جدول ب: درصد فراوانى در هريك از سطوح كيفيت خواب، QEC و

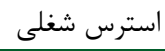

\begin{tabular}{|c|c|c|}
\hline فراوانى (درصد) & & متغير \\
\hline rr/gq & خواب مطلوب & \multirow{2}{*}{ كيفيت خواب } \\
\hline SV/TI & خواب نامطلوب & \\
\hline$\Delta \wedge / \vee \wedge$ & بسيار بالا & \multirow{4}{*}{ QEC } \\
\hline Tr/FQ & بالا & \\
\hline T/TK & متوسط & \\
\hline$\varepsilon / F \Delta$ & يايين & \\
\hline Gr/rA & زياد & \multirow{4}{*}{ استرس شغلى } \\
\hline tVIA & متوسط & \\
\hline$\Delta / \mathcal{F}$ & كم & \\
\hline r/FT & بدون استرس & \\
\hline
\end{tabular}

Q و استرس شغلى را نشان مى دهد. ميانكين نمره كيفيت خواب Tr معادل F

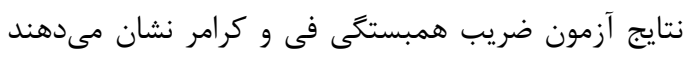

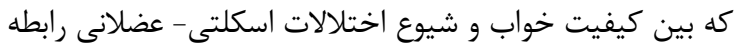

جدول f: ارتباط كيفيت خواب با اختلالات اسكلتى - عضلانى در نواحى بدن

\begin{tabular}{|c|c|c|c|}
\hline سطح معنادارى & فاصله اطمينان (CI) هף درصد & نسبت شانس (OR) & نواحى بدن \\
\hline$\cdot / \cdot 11$ & $\cdot / 4-\cdot / 9 \cdot r$ & $\cdot 10$ & كمر \\
\hline $.1 \cdot 11$ & $\cdot / r-/ F \Delta r$ & $\cdot / \mu$ & 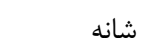 \\
\hline.$/ \cdot r \mu$ & $1 / 1 r-I V / r q$ & $\boldsymbol{k} / \boldsymbol{k} \cdot \boldsymbol{k}$ & زانو \\
\hline
\end{tabular}


جدول ه: ضريب همبستخى Pearson و سطح معنادارى كيفيت خواب با نمره QEC و استرس، سن و سابقه كار

\begin{tabular}{|c|c|c|c|c|c|}
\hline سابقه كار & سن & استرس شغلى & نمره QEC & كيفيت خواب & متغير \\
\hline $\begin{array}{l}\mathrm{R}=\cdot / r \Delta r \\
(\mathrm{P}=\cdot / \cdot r l)\end{array}$ & $\begin{array}{l}\mathrm{R}=\cdot|f r| \\
(\mathrm{P}=\cdot \mid \cdot f)\end{array}$ & $\begin{array}{l}\mathrm{R}=-\cdot / \vee q 4 \\
(\mathrm{P}<\cdot / \cdot \cdot)\end{array}$ & $\begin{array}{l}\mathrm{R}=\cdot 1 \mathrm{\Delta} \wedge 9 \\
(\mathrm{P}<\cdot / \cdot 1)\end{array}$ & & كيفيت خواب \\
\hline $\begin{array}{l}\mathrm{R}=\cdot / \Gamma \Delta \varphi \\
(\mathrm{P}=\cdot / \cdot r)\end{array}$ & $\begin{array}{l}\mathrm{R}=\cdot|r q| \\
(\mathrm{P}=\cdot \mid \cdot r)\end{array}$ & $\begin{array}{l}\mathrm{R}=-\cdot \mid 9 \wedge \Lambda \\
(\mathrm{P}<\cdot / \cdot \cdot 1)\end{array}$ & & $\begin{array}{l}\mathrm{R}=\cdot / 0 \wedge 9 \\
(\mathrm{P}<\cdot / \cdot \cdot 1)\end{array}$ & نمره QEC \\
\hline $\begin{array}{l}\mathrm{R}=-\cdot / r q 9 \\
(\mathrm{P}=\cdot / \cdot r r)\end{array}$ & $\begin{array}{c}\mathrm{R}=-\cdot / T \vee \Lambda \\
(\mathrm{P}=\cdot / \cdot \Delta)\end{array}$ & & $\begin{array}{l}\mathrm{R}=-\cdot \mid 9 \wedge \Lambda \\
(\mathrm{P}<\cdot / \cdot \cdot 1)\end{array}$ & $\begin{array}{l}\mathrm{R}=-\cdot / \text { / } \\
(\mathrm{P}<\cdot / \cdot \cdot 1)\end{array}$ & استرس شغلى \\
\hline \multirow[t]{2}{*}{$\begin{array}{l}\mathrm{R}=\cdot / 9 \mu \omega \\
(\mathrm{P}<\cdot / \cdot \cdot 1)\end{array}$} & & $\begin{array}{c}\mathrm{R}=-\cdot / T V \Lambda \\
(\mathrm{P}=\cdot / \cdot \Delta)\end{array}$ & $\begin{array}{l}\mathrm{R}=\cdot|r q| \\
\left(\mathrm{P}=\cdot \mid \cdot{ }^{\mathrm{c}}\right)\end{array}$ & $\begin{array}{l}\mathrm{R}=\cdot|\mathcal{F}| \\
(\mathrm{P}=\cdot \mid \cdot \boldsymbol{F})\end{array}$ & سن \\
\hline & $\begin{array}{l}\mathrm{R}=\cdot / 9 \mu \Delta \\
(\mathrm{P}<\cdot / \cdot \cdot 1)\end{array}$ & $\begin{array}{l}\mathrm{R}=-\cdot / r q 9 \\
(\mathrm{P}=\cdot / \cdot r r)\end{array}$ & $\begin{array}{l}\mathrm{R}=\cdot / r \Delta \varphi \\
(\mathrm{P}=\cdot / \cdot r)\end{array}$ & $\begin{array}{l}\mathrm{R}=\cdot / r \Delta r \\
(\mathrm{P}=\cdot / \cdot r I)\end{array}$ & سابقه كار \\
\hline
\end{tabular}

فعاليتهاى فيزيكى شديد مانند جابهجايى بيمار و خم شدنهاى

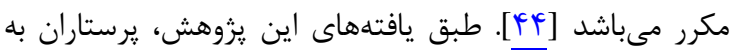

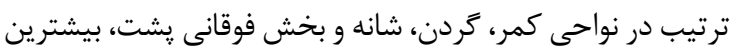

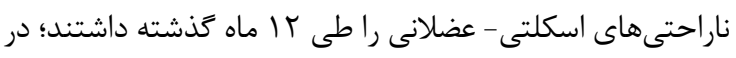

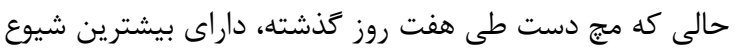

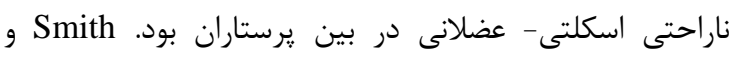

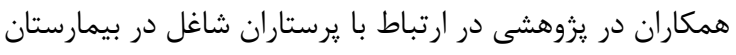

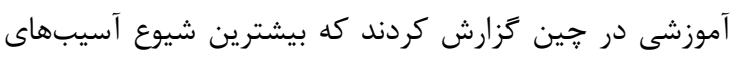

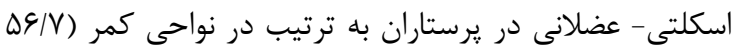

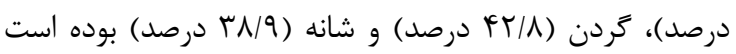

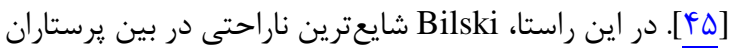

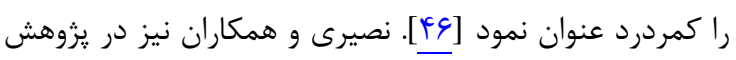

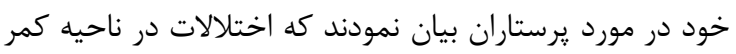

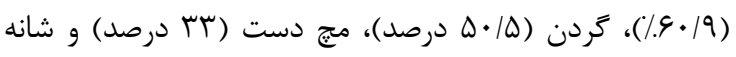

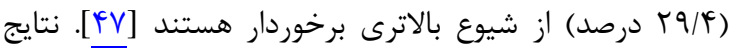

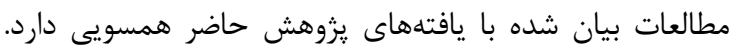

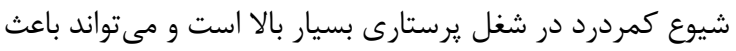

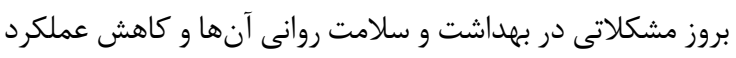

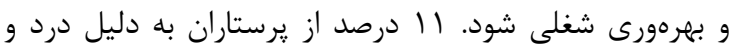

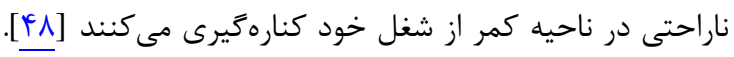

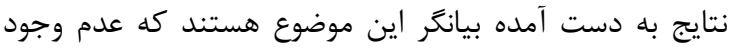

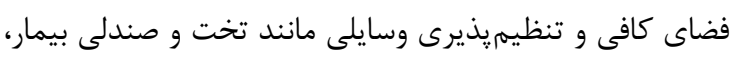

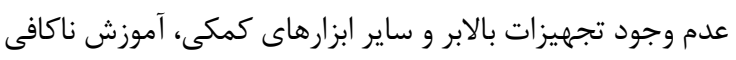
مهارتهاى جابهجايى بيمار و وضعيت صحيح بدن در حين انجام

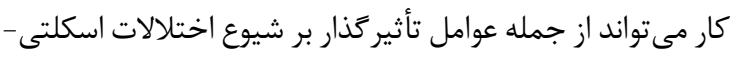

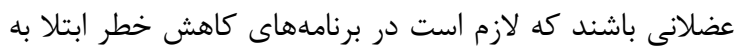

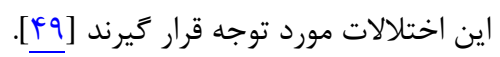

سابقه كار را نشان مىدهد. بر مبناى نتايج، رابطه كيفيت خواب

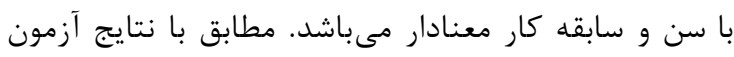

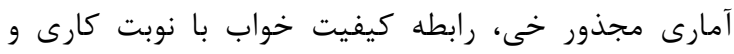

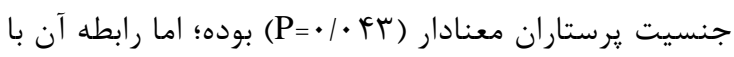
وضعيت تأهل معنادار نمى باشد.

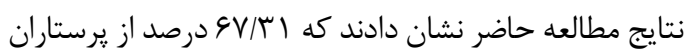
داراى كيفيت خواب نامطلوب هستند. خواجه حسينى و همكاران

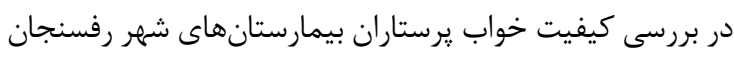

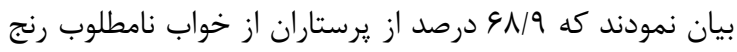

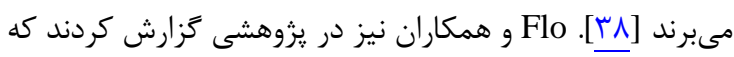

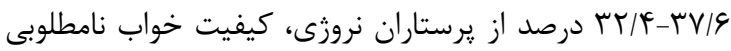

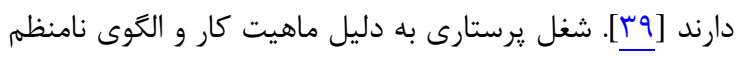

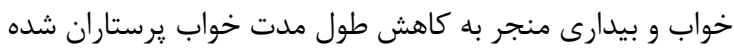

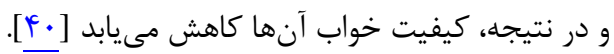

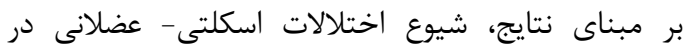

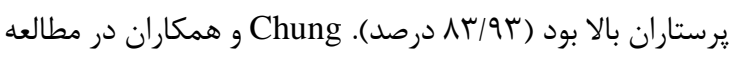

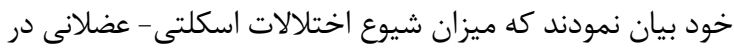

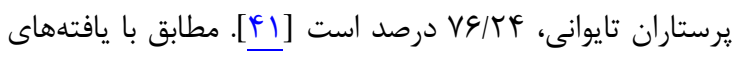

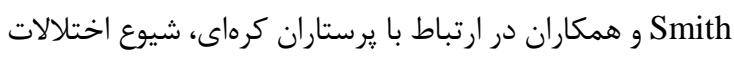

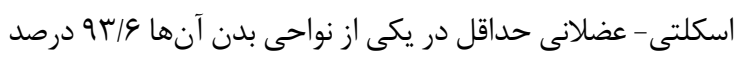

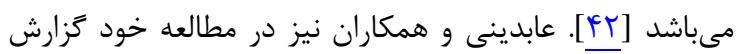

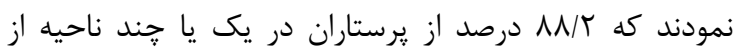

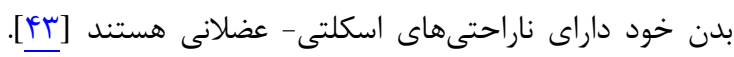

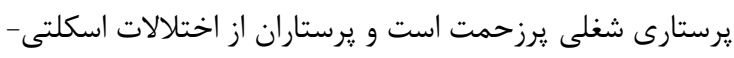

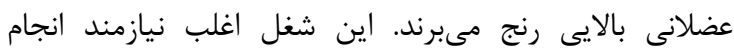


[F] · • نتايج مطالعات باباميرى و همكاران و Auvinen و همكاران

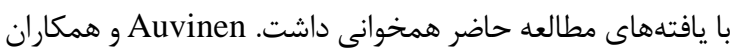

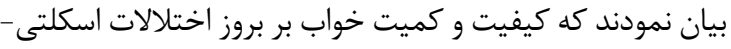

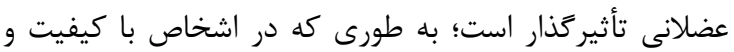

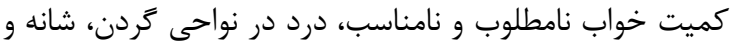

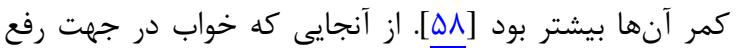

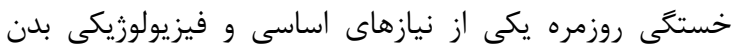

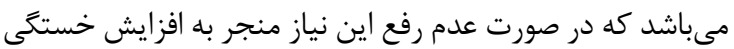

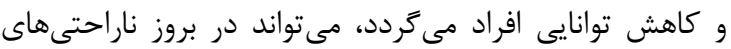
اسكلتى - عضلانى مؤثر باشد [09]. در اين مطالعه كيفيت خواب رابطه معنادارى باشئ استرس

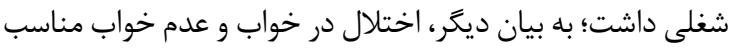

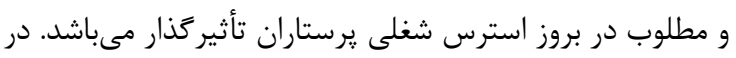

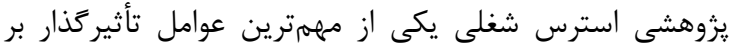

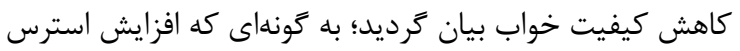

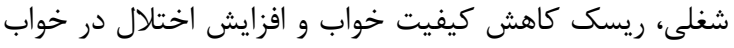

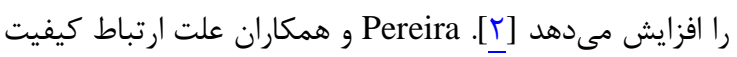

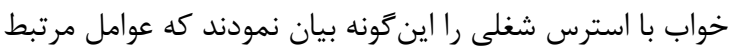

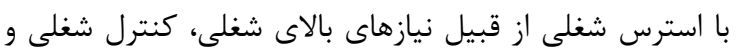

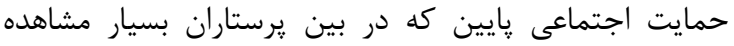

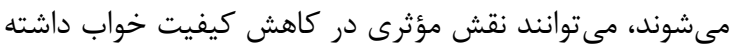

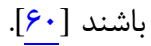
بر مبناى نتايج كيفيت خواب با سن، سابقه كار، نوبت كارى

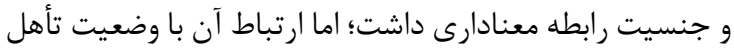

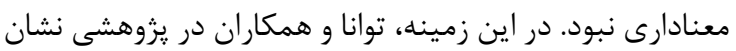

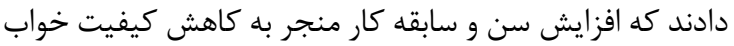

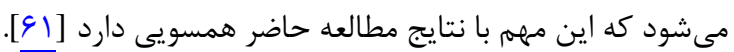

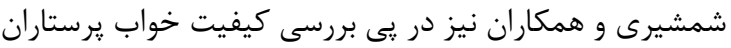

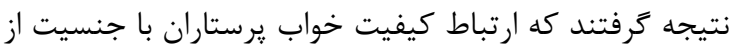

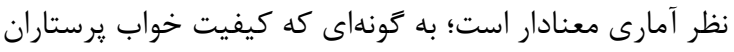

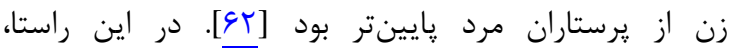
Spoormaker

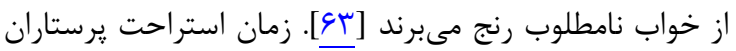

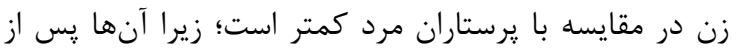

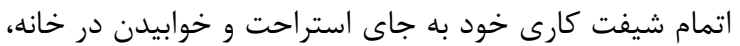

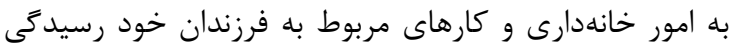

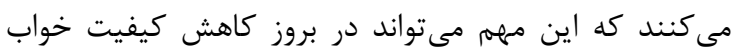

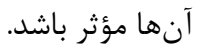

Zhnag و همكاران در مطالعه خود در ارتباط با برستاران

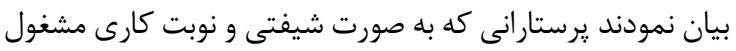

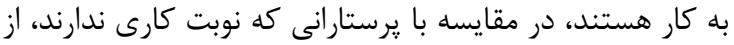

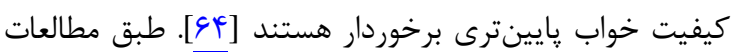
انجام شده، نوبت كارى به دليل كار در شيفت شب و وراعات هابت كارى

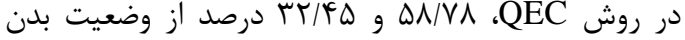

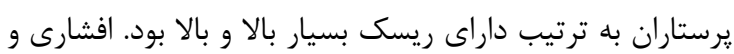

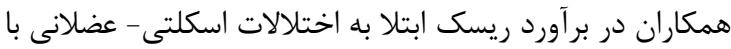

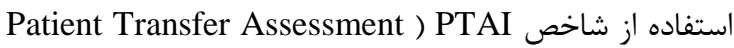

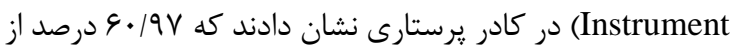
افراد مورد بررسى (بيشترين تعداد افراد) در سطح ريسك بالا در دراد

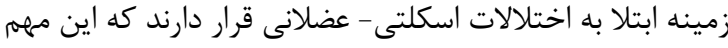

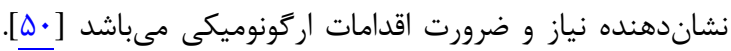

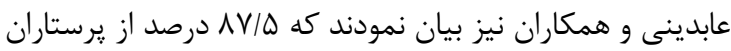
در بالاترين سطح خطر ابتلا به اختلالات اسكلتى - عضلانى قرار

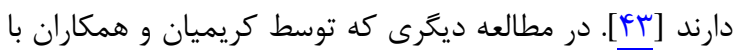

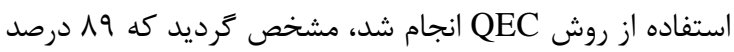

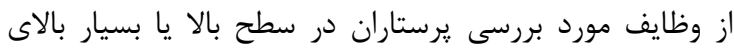

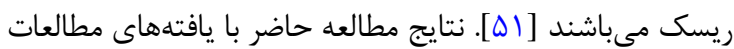

مذكور همخوانى دارد.

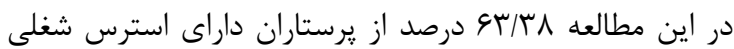

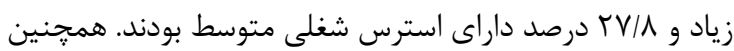

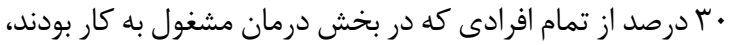

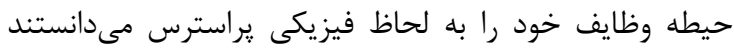

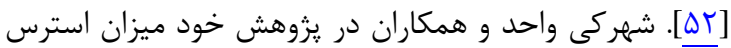

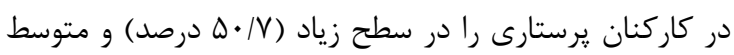

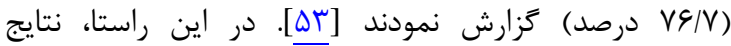

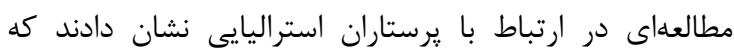

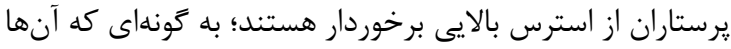

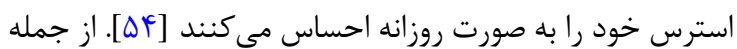
مواردى كه مىتواند سبب ايجاد استرس در محيطهاى كارى

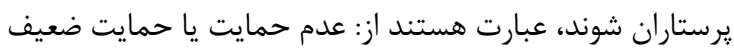

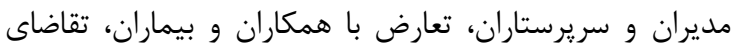

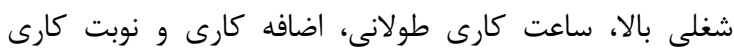

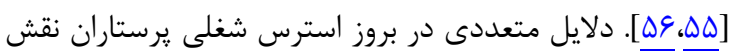

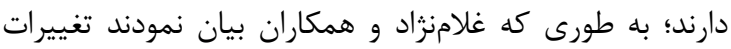

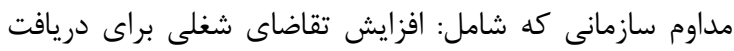

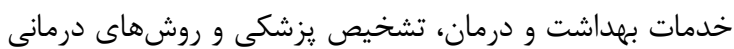

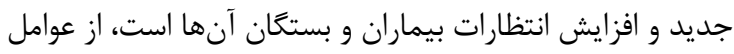

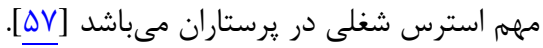

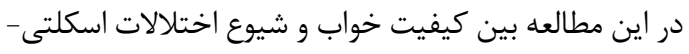

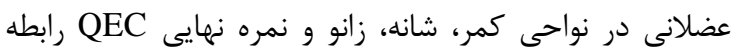

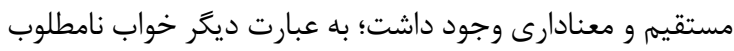

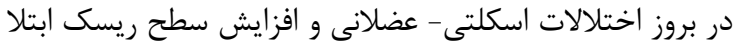

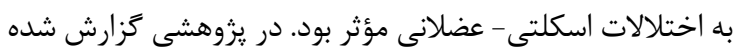
است كه درد و ناراحتى در نواحى اسكلتى - عضلانى بدن، ارتئس ارتباط

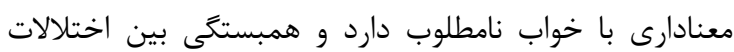

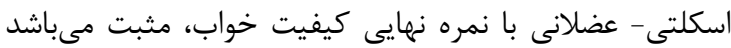


افزايش استرس شغلى آنها مؤثر است. در واقع، كيفيت خواب

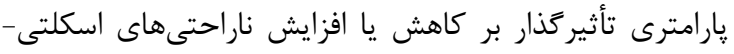

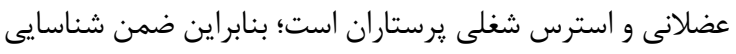

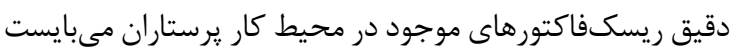

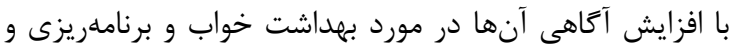

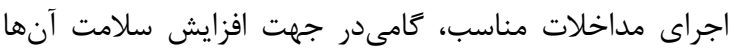
برداشته شود.

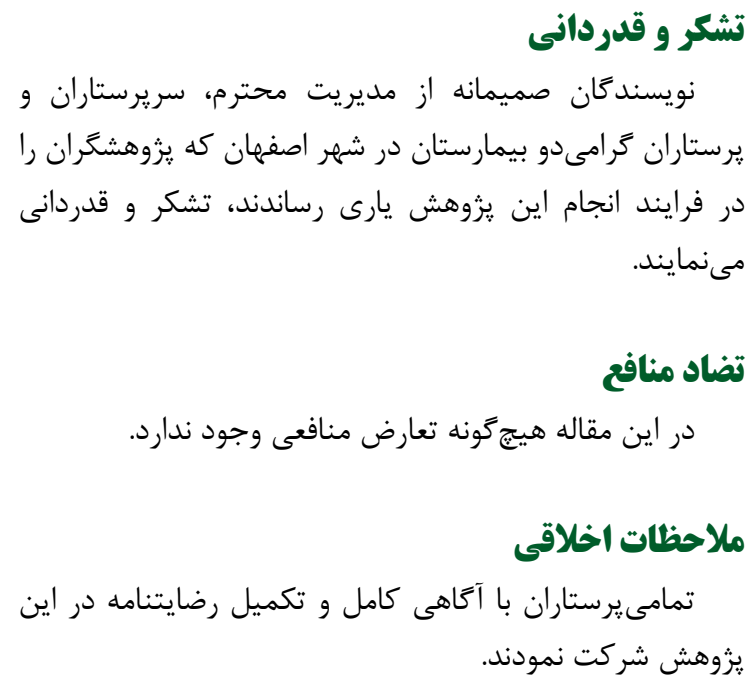

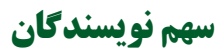
نويسندكان مقاله به نسبت برابر در جمعآورى دآنادهانها، آناليز و نتارش مقاله همكارى داشتهاند. حمايت مالى اين مطالعه از سوى هيج سازمانى حمايت مالى نشده است.

\section{REFERENCES}

1. Tekeoglu I, Ediz L, Hiz O, Toprak M, Yazmalar L, Karaaslan G. The relationship between shoulder impingement syndrome and sleep quality. Eur Rev Med Pharmacol Sci. 2013;17(3):370-4. PMID: 23426540

2. Åkerstedt T, Knutsson A, Westerholm P, Theorell T, Alfredsson L, Kecklund G. Sleep disturbances, work stress and work hours: a cross-sectional study. J Psychosom Res. 2002;53(3):741-8. PMID: 12217447 DOI: 10.1016/s00223999(02)00333-1

3. Ayas NT, White DP, Manson JE, Stampfer MJ, Speizer FE, Malhotra A, et al. A prospective study of sleep duration and coronary heart disease in women. Arch Intern Med. 2003; 163(2):205-9. PMID: 12546611 DOI: 10.1001/archinte. 163.2.205

4. Mehta RK, Horton LM, Agnew MJ, Nussbaum MA. Ergonomic evaluation of hospital bed design features during patient handling tasks. Int J Ind Ergon. 2011;41(6):647-52. DOI: 10.1016/j.ergon.2011.07.005

5. Karahan A, Bayraktar N. Determination of the usage of body mechanics in clinical settings and the occurrence of low back pain in nurses. Int $J$ Nurs Stud. 2004;41(1):67-75. PMID: 14670396 DOI: 10.1016/s0020-7489(03)00083-x

6. Khandan M, Vosoughi S, Poursadeghiyan M, Azizi F, Ahounbar E, Koohpaei A. Ergonomic assessment of posture
طولانى و نامنظم [90] سبب بروز مشكلاتى در سلامتى اشخاص مىشود كه اختلال در خواب، اضطراب، استرس، بيمارىهاى قلبى - عروقى و گوارشى برخى از اين ناراحتى ها مىباشند [ج؟]. بر هم خوردن ريتم سير كادين كه با اختلال در ترشح هورمون همراه است، منجر بله عدم هماهنگى بين سيكل خواب و فعاليتهاى روزمره زندگى مىشود. نوبت كارى يكى از عوامل

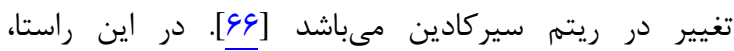
Akerstedt كارى سبب اختلال در خواب مىشود [9V].

محلدوديت هاى مطالعه كوجى بودن حجم نمونه، استفاده از يك بيمارستان براى انجام يزوهش و عدم همكارى برخى از سريرستاران و ״رستاران از محدوديتهاى مطالعه حاضر بود. از آنجايى كه تعداد زيادى از افراد شاغل در محيطهاى بهداشتى و درمانى را يرستاران تشكيل مىدهند، ييشنهاد مى گردد يزوهشى در حجم بسيار بزرگتر و در جندين بيمارستان خصوصى و دولتى در مناطق مختلف كشور انجام شود و ساير متغيرها از قبيل فرسودگى، رضايت شغلى، بهرهورى و شرايط فيزيكى محيط كار به همراه معاينات بالينى يرستاران براى تشخيص يزشكى ناراحتى هاى اسكلتى - عضلانى، تأثير مداخلاتى از قبيل آموزش و افزايش آحًاهى در زمينس اختلالات اسكلتى - عضلانى، مديريت استرس شغلى و بهداشت خواب نيز مورد بررسى قرار گيرد.

\section{نتبحهن}

نتايج اين مطالعه نشان دادند كه كاهش كيفيت خواب و افزايش اختلال خواب يرستاران در افزايش شيوع اختلالات اسكلتى - عضلانى، افزايش سطح ريسك ابتلا به اختلالات و

risk factors among Iranian Workers: an alternative to conventional methods. Iran Rehabil J. 2018;16(1):11-6. DOI: 10.29252/nrip.irj.16.1.11

7. Denis D, St-Vincent M, Imbeau D, Jette C, Nastasia I. Intervention practices in musculoskeletal disorder prevention: a critical literature review. Appl Ergon. 2008;39(1):1-14. PMID: 17506975 DOI: 10.1016/j.apergo. 2007.02.002

8. Karwowski W, Marras WS. The occupational ergonomics handbook. Florid: CRC Press; 1998.

9. Liang CA, Levine VJ, Dusza SW, Hale EK, Nehal KS. Musculoskeletal disorders and ergonomics in dermatologic surgery: a survey of Mohs surgeons in 2010. Dermatol Surg. 2012;38(2):240-8. PMID: 22212027 DOI: $10.1111 / \mathrm{j} .1524-$ 4725.2011.02237.x

10. Choobineh A. Posture assessment methods in occupational ergonomics. Hamedan: Fanavaran Publication; 2004. [Persian]

11. Herin F, Paris C, Levant A, Vignaud MC, Sobaszek A, Soulat JM. Links between nurses' organisational work environment and upper limb musculoskeletal symptoms: Independently of effort-reward imbalance! The ORSOSA study. Pain. 2011;152(9):2006-15. PMID: 21570771 DOI: 10.1016/ j.pain.2011.04.018 
12. Nasl Saraji J, Ghaffari M, Shahtaheri SJ. Survey of correlation between two evaluation method of work related musculoskeletal disorders risk factors REBA \& RULA. Iran Occup Health. 2006;3(2):5. [Persian]

13. Choobineh A, Solaymani E, Mohammad BA. Musculoskeletal symptoms among workers of metal structure manufacturing industry in Shiraz, 2005. Iran J Epidemiol. 2009;5(3):35-43. [Persian]

14. Aasa U, Barnekow-Bergkvist M, Ängquist KA, Brulin C. Relationships between work-related factors and disorders in the neck-shoulder and low-back region among female and male ambulance personnel. J Occup Health. 2005;47(6):4819. PMID: 16369110 DOI: $10.1539 /$ joh.47.481

15. Aggarwal NT, Wilson RS, Beck TL, Rajan KB, De Leon CFM, Evans DA, et al. Perceived stress and change in cognitive function among adults aged 65 and older. Psychosom Med. 2014;76(1):80-5. PMID: 24367123 DOI: 10.1097/PSY.0000000000000016

16. Molla Agha Babaei AH, Yazdi M, Barakat S. Prevalence of musculoskeletal disorders and its relationship with occupational stress among workers at a steel industry. Iran Occup Health. 2016;13(3):63-72. [Persian]

17. Chrousos GP. Stress: basic mechanisms and clinical implications. New York: Academy of Sciences; 1995.

18. Almanza A, Carlesso A, Chintha C, Creedican S, Doultsinos D, Leuzzi B, et al. Endoplasmic reticulum stress signalling-from basic mechanisms to clinical applications. FEBS J. 2019; 286(2):241-78. PMID: 30027602 DOI: $10.1111 / \mathrm{febs} .14608$

19. van Rijn R, Carlier B, Schuring M, Burdorf A. Occupational and environmental medicine. Health, social participation and entering paid employment among unemployed persons. Rotterdam, Netherlands: Erasmus University Rotterdam; 2016. P. 73-91.

20. Tangri R. Stress costs, stress cures. Indiana: Trafford Publishing; 2003.

21. Paton N. UK study links stress and musculoskeletal disorders. Occup Health Wellbeing. 2004;56(12):4.

22. AlHajjar B. Occupational stress among hospital nurses in Gaza-Palestine. Manchester: University of Manchester; 2013.

23. Attal N, Masselin-Dubois A, Martinez V, Jayr C, Albi A, Fermanian J, et al. Does cognitive functioning predict chronic pain? Results from a prospective surgical cohort. Brain. 2014;137(Pt 3):904-17. PMID: 24441173 DOI: 10.1093/ brain/awt354

24. Choi SM, Park YS, Yoo JH, Kim GY. Occupational stress and physical symptoms among family medicine residents. Korean J Fam Med. 2013;34(1):49-57. PMID: 23372906 DOI: $10.4082 / \mathrm{kjfm} .2013 .34 .1 .49$

25. Haghdoost AA, Hajihosseini F, Hojjati H. Relationship between the musculoskeletal disorders with the ergonomic factors in nurses. Koomesh. 2011;12(4):372-8. [Persian]

26. Eatough EM, Way JD, Chang CH. Understanding the link between psychosocial work stressors and work-related musculoskeletal complaints. Appl Ergon. 2012;43(3):554-63. PMID: 21944295 DOI: 10.1016/j.apergo.2011.08.009

27. Gonçalves MB, Fischer FM, Lombardi M, Ferreira RM. Work activities of practical nurses and risk factors for the development of musculoskeletal disorders. J Hum Ergol. 2001;30(1-2):369-74. PMID: 14564910

28. Piedrahita H. Costs of work-related musculoskeletal disorders (MSDs) in developing countries: Colombia case. Int J Occup Saf Ergon. 2006;12(4):379-86. PMID: 17156613 DOI: $10.1080 / 10803548.2006 .11076696$

29. Ross RR, Altmaier EM. Intervention in occupational stress: a handbook of counselling for stress at work. California: Sage; 1994.

30. Barakat S, Javan M, Dehghan H, Habibi E. Ergonomic assessment of body posture during work using the Rapid Entire Body Assessment method and prevalence of musculoskeletal disorders in dental students. J Isfahan Dent Sch. 2013;9(5):423-32. [Persian]

31. Babamiri M, Heidarimoghadam R, Saidnia H, Mohammadi Y, Joudaki J. Investigation of the role of mental workload, fatigue, and sleep quality in the development of musculoskeletal disorders. J Occup Hyg Eng Volume. 2019;5(4):1-7. [Persian] DOI: 10.22222/johe.5.4.1
32. Mokhtarinia H, Shafiee A, Pashmdarfard M. Translation and localization of the Extended Nordic Musculoskeletal Questionnaire and the evaluation of the face validity and testretest reliability of its Persian version. Iran J Ergon. 2015;3(3):21-9. [Persian]

33. Choobineh A, Daneshmandi H, Poor AF, Fard HR. Ergonomic assessment of musculoskeletal disorders risk level among workers of a petrochemical company. Iran Occup Health. 2013;10(3):78-88. [Persian]

34. David G, Woods V, Buckle P, Stubbs D. Further development of the Quick exposure Check (QEC). Ergonomics in the digital age. The XVth Triennial Congress of the International Ergonomics Association, Seoul, Korea; 2003.

35. Cousins R, Mackay CJ, Clarke SD, Kelly C, Kelly PJ, McCaig RH. 'Management standards' work-related stress in the UK: Practical development. Work Stress. 2004; 18(2):113-36. DOI: 10.1080/02678370410001734322

36. Azad ME, Gholami FM. Reliability and validity assessment for the HSE job stress questionnaire. J Behav Sci. 2011; 4(4):291-7. [Persian]

37. Jafari N, Bakhshi E, Moradi A, Asadi H, Naderi M. Assessment of demographic and job related stressors on depression, stress and anxiety in employees of Islam Abad Gharb Health Centers. J Health. 2018;9(4):403-13. [Persian] DOI: $10.29252 /$ j.health.9.4.403

38. Khajeh Hosseini S, Sayadi A, Mobini Lotfabad M, Heidari S. Sleep Quality among shift-working nurses in the hospitals of Rafsanjan city, Iran, in 2018. Health Dev J. 2019;8(2):14151. [Persian] DOI: 10.22034/8.2.141

39. Flo E, Pallesen S, Magerøy N, Moen BE, Grønli J, Nordhus IH, et al. Shift work disorder in nurses-assessment, prevalence and related health problems. PloS One. 2012;7(4):e33981. PMID: 22485153 DOI: 10.1371/journal.pone.0033981

40. Samaha E, Lal S, Samaha N, Wyndham J. Psychological, lifestyle and coping contributors to chronic fatigue in shiftworker nurses. J Adv Nurs. 2007;59(3):221-32. PMID: 17590207 DOI: 10.1111/j.1365-2648.2007.04338.x

41. Chung YC, Hung CT, Li SF, Lee HM, Wang SG, Chang SC, et al. Risk of musculoskeletal disorder among Taiwanese nurses cohort: a nationwide population-based study. BMC Musculoskelet Disord. 2013;14(1):144. PMID: 23617330 DOI: 10.1186/1471-2474-14-144

42. Smith DR, Choe MA, Yang Jeon M, Ran Chae Y, Ju An G, Sim Jeong J. Epidemiology of musculoskeletal symptoms among Korean hospital nurses. Int J Occup Saf Ergon. 2005;11(4):431-40. PMID: 16329786 DOI: 10.1080/ 10803548.2005.11076663

43. Abedini R, Choobineh A, Hasanzadeh J. Musculoskeletal load assessment in hospital nurses with patient transfer activity. Int J Occup Hyg. 2013;5(2):39-45.

44. Kee D, Seo SR. Musculoskeletal disorders among nursing personnel in Korea. Int J Ind Ergon. 2007;37(3):207-12. DOI: 10.1016/j.ergon.2006.10.020

45. Smith DR, Wei N, Kang L, Wang RS. Musculoskeletal disorders among professional nurses in mainland China. $J$ Prof Nurs. 2004;20(6):390-5. PMID: 15599873 DOI: 10.1016/j.profnurs.2004.08.002

46. Bilski B, Sykutera L. Determinants of musculoskeletal system load and their health effects among nurses from four Poznan hospitals. Med Pr. 2004;55(5):411-6. PMID: 15768894

47. Nasiry Zarrin Ghabaee D, Haresabadi M, Bagheri Nesami M, Esmaeili R, Talebpour Amiri F. Musculoskeletal disorders in nurses and their relationship with occupation-related stress. $J$ Mazandaran Univ Med Sci. 2016;25(132):91-102. [Persian]

48. Maul I, Läubli T, Klipstein A, Krueger H. Course of low back pain among nurses: a longitudinal study across eight years. Occup Environ Med. 2003;60(7):497-503. PMID: 12819283 DOI: 10.1136/oem.60.7.497

49. Habibi E, Farrokhi E, Mansourian M. Assessment of nursesl'patient transfer technique with DINO method and compare it with MAPO method in estimation musculoskeletal disorders risk. J Prev Med. 2016;2(4):50-7. [Persian]

50. Afshari D, Amir Moezi S, Moosavian Asl Z. Estimating the risk of musculoskeletal disorders in nursing staff by using indicators of musculoskeletal disorders (MAPO AND PTAI). 
J Neyshabur Univ Med Sci. 2018;5(4):71-9. [Persian]

51. Karimian R, Rahnama N, Karimian M, Janbozorgi A. Ergonomic evaluation of the risk of suffering from musculoskeletal disorders in nurses with quick exposure check (QEC) and the effect of 8-week selected corrective exercises and ergonomic occupational intervention on their exposure rate. J Fasa Univ Med Sci. 2015;5(2):210-8. [Persian]

52. Abedini R, Choobineh A, Hasanzadeh J. Musculoskeletal disorders related to patient transfer in hospital nursing personnel. J Health Syst Res. 2012;8(3):385-96. [Persian]

53. Mardani Hamouleh M, Shahraki Vahed A, Moshtagh Eshgh Z. Assessment of the relationship between mental health and job stress among nurses. Pars J Med Sci. 2010;8(3):34-40. [Persian] DOI: 10.29252/jmj.8.2.35

54. Dermody K, Bennett PN. Nurse stress in hospital and satellite haemodialysis units. J Ren Care. 2008;34(1):28-32. PMID: 18336520 DOI: 10.1111/j.1755-6686.2008.00007.x

55. Chayu T, Kreitler S. Burnout in nephrology nurses in Israel. Nephrol Nurs J. 2011;38(1):65-77. PMID: 21469556

56. Garrosa E, Rainho C, Moreno-Jimenez B, Monteiro MJ. The relationship between job stressors, hardy personality, coping resources and burnout in a sample of nurses: a correlational study at two time points. Int J Nurs Stud. 2010;47(2):205-15. PMID: 19596324 DOI: 10.1016/j.ijnurstu.2009.05.014

57. Forsberg E. Do financial incentives make a difference? A comparative study of the effects of performance-based reimbursement in Swedish health care. [Doctoral Dissertation]. Sweden: Acta Universitatis Upsaliensis; 2001.

58. Auvinen JP, Tammelin TH, Taimela SP, Zitting PJ, Järvelin $\mathrm{MR}$, Taanila AM, et al. Is insufficient quantity and quality of sleep a risk factor for neck, shoulder and low back pain? A longitudinal study among adolescents. Eur Spine $J$. 2010;19(4):641-9. PMID: 19936804 DOI: $10.1007 / \mathrm{s} 00586-$ 009-1215-2

59. Shattuck NL, Matsangas P, Moore J, Wegemann L. Prevalence of musculoskeletal symptoms, excessive daytime sleepiness, and fatigue in the crewmembers of a US Navy ship. Mil Med. 2016;181(7):655-62. PMID: 27391619 DOI: 10.7205/MILMED-D-15-00279

60. Pereira D, Elfering A. Social stressors at work, sleep quality and psychosomatic health complaints--a longitudinal ambulatory field study. Stress Health. 2014;30(1):43-52. PMID: 23824588 DOI: $10.1002 /$ smi.2494

61. Tawana H, Rezagholy P, Ebrahimzadeh M. The relationship between sleep quality and job stress in nurses working in educational hospitals of Kurdistan University of Medical Sciences in 2014. J Jiroft Univ Med Sci. 2018;5(1):306-14. [Persian]

62. Shamshri M, Moshki M, Mogharab M. The survey of sleep quality and its relationship to mental health of hospital nurses. Iran Occup Health J. 2014;11(3):96-104. [Persian]

63. Spoormaker VI, van den Bout J. Depression and anxiety complaints; relations with sleep disturbances. Eur Psychiatry. 2005;20(3):243-5. PMID: 15935423 DOI: 10.1016/j.eurpsy. 2004.11.006

64. Zhang L, Sun DM, Li CB, Tao MF. Influencing factors for sleep quality among shift-working nurses: a cross-sectional study in China using 3-factor Pittsburgh sleep quality index. Asian Nurs Res. 2016;10(4):277-82. PMID: 28057314 DOI: 10.1016/j.anr.2016.09.002

65. Srivastava UR. Shift work related to stress, health and mood states: a study of dairy workers. $J$ Health Manag. 2010;12(2):173-200. DOI: 10.1177/097206341001200205

66. Kim JY, Chae CH, Kim YO, Son JS, Kim JH, Kim CW, et al. The relationship between quality of sleep and night shift rotation interval. Ann Occup Environ Med. 2015;27(1):31. PMID: 26688731 DOI: 10.1186/s40557-015-0084-X

67. Åkerstedt T, Fredlund P, Gillberg M, Jansson B. Work load and work hours in relation to disturbed sleep and fatigue in a large representative sample. J Psychosom Res. 2002;53(1):585-8. PMID: 12127175 DOI: 10.1016/s00223999(02)00447-6 